\title{
Desenvolvimento local e Qualidade de vida na percepção de agricultoras no Assentamento Mulunguzinho em Mossoró-RN
}

\author{
Zildenice Matias Guedes Maia
}

Universidade Federal do Rio Grande do Norte, Natal-RN, Brasil.

Email: zildenice@hotmail.com

\section{Elisabete Stradiotto Siqueira}

Universidade Federal Rural do Semi-árido, Mossoró-RN, Brasil.

Email: betebop@uol.com.br

\section{CimoneRozendo}

Universidade Federal do Rio Grande do Norte, Natal-RN,Brasil

Email: cimone.rozendo@gmail.com

\begin{abstract}
Resumo: Os assentamentos de reforma agrária no Brasil têm sido concebidos como possibilidade de enraizamento de uma clientela excluída dos processos mais gerais de desenvolvimento econômico e,também como mecanismo de dinamização dos espaços rurais ancorados às noções de desenvolvimento sustentável e com forte apelo à noção de qualidade de vida. Assim, o objetivo dessa pesquisa foi investigar a percepção de e agricultoras familiares do Assentamento Mulunguzinho em Mossoró-RN, região semiárida do Brasil, sobre qualidade de vida. A pesquisa tomou como referencia a trajetória de duas famílias assentadas buscando evidenciar por meio de seus relatos os elementos que designam como qualidade de vida. Além disso, com o uso de câmeras fotográficas os próprios entrevistados registraram tais aspectos. Identificou-se que o espaço rural é concebido pelas agricultoras como um lugar de qualidade de vida por natureza, por todos os recursos (alimento, água) que pode oferecer. $\mathrm{O}$ acesso à moradia aparece como expressão prevalecente de qualidade de vida no assentamento.
\end{abstract}

Palavras-Chave: Desenvolvimento, agricultura familiar, qualidade de vida.

\section{Desarrollo local y calidad de vida en la percepción de agricultoras en el asentamiento Mulunguzinho en Mossoró (RN)}

Resumen: Los asentamientos de la reforma agraria en Brasil han sido concebidos como posibilidades de arraigo de una clientela excluída de los procesos más generales de desarrollo económico y, también como mecanismo de dinamización de los espacios rurales anclados en las nociones de desarrollo sustentable y con fuerte llamamiento a la noción de calidad de vida. Así, el objetivo de esta investigación fue 
indagar la percepción de las familias agricultoras del asentamiento Mulunguzinho en Mossoró (RN), región semiárida de Brasil, sobre la calidad de vida. La investigación tomó como referencia la trayectoria de dos familias asentadas, buscando evidenciar por medio de sus relatos los elementos que designan como calidad de vida. Más allá de eso, con el uso de cámaras fotográficas, los propios entrevistados grabaron tales aspectos. Se identificó que el espacio rural está concebido por las agricultoras como un lugar de calidad de vida por naturaleza, por todos los recursos (alimento, agua) que puede ofrecer. El acceso a la vivienda aparece como expresión prevaleciente de calidad de vida en el asentamiento.

Palabras Clave: Desarrollo, agricultura familiar, calidad de vida

\title{
Local development and quality of life in the perception of the farmers of the Mulunguzinho settlement in Mossoró (RN)
}

\begin{abstract}
The settlements in Land Reform in Brazil have been designed as possibilities to root a clientele excluded from more general processes of economic development, and also as stimulation mechanisms for rural areas anchored in the notions of sustainable development and with strong appeal to the notion of quality of life. In this way, the objective of this research was to investigate the perception of farmers' families from the settlement Mulunguzinho in Mossoró (RN), semiarid region in Brazil, about quality of life. The research took as a reference the trajectory of two settled families, to seek disclosing, through their stories, the elements designated as quality of life. Furthermore, using picture cameras, the own interviewees recorded such aspects. We identified that rural space is conceived by farmers as a place of quality of life by nature, for all resources (food, water) it can offer. The access to housing appears as a prevailing expression for quality of life in settlements.
\end{abstract}

Keywords: Development, family farming, quality of life.

\section{Introdução}

Ao mesmo tempo em que o século XX representou um avanço para a humanidade do ponto de vista científico-tecnológico, consistiu igualmente em processos que degradaram aspectos da qualidade de vida humana e da sustentabilidade ambiental. Foi o século de duas guerras mundiais e intensificação da depredação dos recursos naturais. Conforme Santos (2002) tal cenário incorreu em uma transição paradigmática quequestiona o paradigma da modernidade ocidental presente a partir dos séculos XVI e XVII, e que se “impõe como um ambicioso e revolucionário paradigma sócio-cultural assente numa tensão dinâmica entre regulação social e emancipação social”. (p.10)

A partir da crise do paradigma dominante, intensificam-se argumentos que reforçam a necessidade de outro modelo de desenvolvimento que incorpore a preocupação com o capital natural, assim como com a vida humana. Nesse sentido, mostra-se de fundamental importância mudanças sociais nesse processo. Sobretudo, aquelas que conduzam a práticas sustentáveis em todas as escalas (Medeiros, 2013). 
As críticas contumazes sobre a exploração dos recursos naturais e a consequente perda desse capital são identificadas na Inglaterra desde o século XVII. Nesse momento já se denunciava as agressivas devastações causadas nas florestas inglesas decorrentes da construção de barco, bem como manufaturas de vidro, fornalhas de ferro, dentre outros (Foster, 2005). Diversas teorias detiveram-se a explicar o afastamento do ser humano da natureza, reduzindo tal relação ao utilitarismo, contudo, as críticas a essa perspectiva surgem a partir do momento que se observa as causas da degradação humana sobre o capital natural, e como a natureza vai respondendo a essas ações. Nesse sentido, além das críticas e denúncias que se intensificam, exige-se da raça humana outra compreensão da natureza, que, sobretudo, evoque um olhar que respeite a capacidade do meio ambiente, em que homem e mulher se sintam parte integrante da natureza (Leff, 2006;Foster,2005;Santos, 2006).

Dentre alguns marcos conceituais dessa discussão, é mister ressaltar as inquietações que emergem especificamente por volta dos anos de 1960, e se proliferam em alertas vindos da Universidade, quando se discute sobre o avanço das ciências que incorre por transformar as tecnologias e processos produtivos em verdadeiras ameaças à perenidade da vida. Expoentes dessa discussão são algumas obras, como Silent Spring(Carson, 1962)The trageyofthecommons(Hardin, 1968).

Este cenário demonstra a preocupação que tem permeado a sociedade em relação à perspectiva ambiental e por sua vez, da relação humana com o meio ambiente. E neste contexto que a ideia de sustentabilidade, ganha evidência, uma vez que entende-se que este se baseia na valorização das características e capacidades endógenas, no empoderamento dos indivíduos locais, enquanto portadores da capacidade de promover seu desenvolvimento em parceria com outros âmbitos da sociedade, como o Estado e o setor privado. Nessa lógica o desenvolvimento estaria articulado à possibilidade do homem viver bem, para além da visão econômica que toma como equivalentes qualidade de vida e capacidade de consumo.Significa, portanto, entender que "a condição de agente livre e sustentável emerge como um motor fundamental do desenvolvimento" (Sen 2010, p.18).

Destarte, (Ibid, p. 110)propõe uma concepção de desenvolvimento, que difere das abordagens que vigoravam até então. Ele considera que a condição de agente dos indivíduos é fundamental para que tal perspectiva se realize. $\mathrm{O}$ autor acredita que a liberdade individual consiste em um comprometimento social, que coloca os indivíduos como protagonistas da realidade na qual estão inseridos, conferindo-lhes autonomia para atuarem como partícipes, e por sua vez, esta atuação será refletida na sociedade como um todo. Diante dessa perspectiva, Sen (2010:16) afirma "ver o desenvolvimento como expansão de liberdades substantivas dirige a atenção para os fins que o tornam importante, em vez de restringi-la a alguns meios que, inter alia ${ }^{1}$, desempenham um papel relevante no processo”. 
Entende-se que o desenvolvimento endógeno é capaz de fortalecer a autogestão das comunidades, de modo que estas não sejam vistas como pauperizadas, mas como protagonistas de suas próprias condições de existência. $\mathrm{O}$ protagonismo dos atores ou sua autonomia, também está na base das reflexões de Buarque(2008) sobre desenvolvimento local. Este é concebido como "o resultado de múltiplas ações convergentes e complementares, capaz de quebrar a dependência e a inércia do subdesenvolvimento e do atraso em localidades periféricas e de promover uma mudança social no território”. (p.26)

Mas como essa autonomia e protagonismo, que conformam a base da noção de sustentabilidade, são construídas no cotidiano das sociedades? Quais valores e condições materiais são considerados pelos atores sociais como patamares básicos da sua qualidade de vida, e por consequência, que elementos sãofundamentais do desenvolvimento sustentável?. Nesse sentido, buscou-se compreender estas questões a partir da percepçãodos atores que estão implicados em estratégias de desenvolvimento, no caso específico de um projeto de Reforma Agrária, na região Nordeste do Brasil. Considerando quea qualidade de vida não consiste apenas naquilo que é determinado como necessidades básicas, mas sim o que eles almejam no que diz respeito aos medos, sonhos, perspectivas. Logo, a perspectiva da qualidade de vida consistiu em um aporte teórico e empírico para dialogar com o desenvolvimento sob a percepção das agricultoras. A respeito da percepção, afirma Pontual(2002)

“A questão da percepção da população é um ponto de partida fundamental para uma pedagogia de participação da inclusão, que busque construir não só novos resultados ou indicadores de qualidade de vida, mas, sobretudo, produzir novos significados de qualidade de vida”(p.201)

Nesse contexto, considerando que o desenvolvimento está além de uma perspectiva econômica, e que tem o papel fundamental de proporcionar qualidade de vida para a população, indaga-se sobre que dimensões deste processo são valorizadas pela população, particularmente, aquela que vive no campo muitas vezes com recursos e acessos limitados aos serviços públicos. Nesse sentido, o objetivo da pesquisa consistiu em investigar a percepção de agricultoras familiares residentes no Assentamento Mulunguzinho em Mossoró-RN sobre qualidade de vida no campo, procurando identificar que tipo de modelo de desenvolvimento está presente em tal concepção.

Destarte, a pergunta que norteou a pesquisa tratou de questionar que sentido o espaço rural confere as agricultoras do Assentamento Mulunguzinho, como estas pessoas percebem a qualidade de vida em seu local de moradia, e em que medida a qualidade de vida relaciona-se com a autonomia e o desenvolvimento local. 


\section{O rural como lócus de qualidade de vida}

Uma abordagem que pretenda trabalhar com a perspectiva da qualidade de vida deve considerar que tal tarefa implica numa expedição complexa, considerando que a aplicação de um método, ou mesmo vários, encontrará sempre limitações. O sucesso de tal perspectiva está relacionado à postura do observador frente ao objeto de investigação, pois não há como mensurar a melhor percepção no que diz respeito à qualidade de vida. "Quem melhor pode definir qualidade de vida, quem vive ou quem observa?” (Martins et al., 2000, p. 64). O conceito de qualidade de vida adotado neste trabalho baseia-se em Herculano (1998) que assim o define:

“Propomos que 'qualidade de vida' seja definida como a soma das condições econômicas, ambientais, científico-culturais e políticas coletivamente construídas e postas à disposição dos indivíduos para que estes possam realizar suas potencialidades: inclui a acessibilidade à produção e ao consumo, aos meios para produzir cultura, ciência e arte, bem como pressupõe a existência de mecanismos de comunicação, de informação, de participação e de influência nos destinos coletivos”. (p.22)

Portanto, entende-se que para discutir sobre qualidade de vida é necessário articula-la à perspectiva do desenvolvimento, pois são conceitos que dialogam em suas fronteiras. De acordo com Sen (2010), a concepção adequada de desenvolvimento deve ir muito além do crescimento do Produto Nacional Bruto, e mesmo de muitos índices que visam mensurar quantitativamente o aumento de renda da população. Nesse sentido, não se pode desconsiderar a importância do crescimento econômico e mesmo aumento da renda per capita. Contudo, esses devem se constituir em meios para melhorar a qualidade de vida da população, devendo esse ser o fim de uma perspectiva adequada do desenvolvimento. Diante disso, afirma(Sen):

"Com efeito, dada a diversidade interpessoal, relacionada a fatores como idade, sexo, talentos inatos, incapacidades e doenças, o conjunto de bens possuídos pode efetivamente nos dizer pouquíssimo sobre a natureza da vida que cada pessoa pode levar. Portanto, as rendas reais podem ser indicadores muito insatisfatórios dos componentes importantes do bem-estar e da qualidade de vida que as pessoas têm razão para valorizar” (p.111)

Corroborando com Sen (2010), Herculano (1998) afirma “a qualidade de vida não deve, portanto, ser entendida como um mero conjunto de bens, confortos e serviços, mas, através destes, das oportunidades efetivas das quais as pessoas dispõem para ser” (p.10). De acordo com Vitte(2002), a discussão sobre a qualidade de vida deve ser vista como uma das premissas norteadoras na busca do desenvolvimento, e deve ainda ser considerada como um direito de cidadania. Ao citar a experiência social-democrata da Escandinávia na perspectiva da qualidade de vida, a referida autora apresenta os princípios dessa experiência com base em três verbos: ter, amar e ser. Ao 
verbo ter refere-se às condições materiais necessárias à sobrevivência, recursos econômicos, condições de habitação, o emprego, as condições físicas do trabalho, saúde e educação. Ao verbo amar refere-se à necessidade de relacionar com outras pessoas e criar identidades sociais. $\mathrm{O}$ verbo ser refere-se às necessidades de integração com a natureza, e ainda participação nas decisões políticas. Embora (Ibid)reconheça que essa experiência apresenta um caráter subjetivo, e que, portanto, é difícil de mensurar, o que é relevante é a participação da população nesse processo, sendo-lhes conferida a possibilidade de eles mesmos interferirem nas decisões que dizem respeito à coletividade, e que pode resultar em políticas públicas que visem a favorecer a sociedade.

A noção de qualidade de vida tem sido aproximada ao grau de satisfação presente na vida familiar, amorosa, social e ambiental, ou ainda à própria estética existencial. Nesse sentido propõe a capacidade de integrar elementos que vão desde a cultura até aqueles que determinada sociedade reconhece como seu padrão de conforto e bem-estar.

Destarte, abordando o desenvolvimento e qualidade de vida em uma perspectiva ampla, entende-se que o campo configura-se como um lócus de reprodução de vida, em que formas de vida pretérita se mantém, ao passo que novas configurações surgem, de modo que a tessitura da vida dos atores está relacionada a aspectos quantitativos e econômicos, assim como aos aspectos afetivos e emocionais.

Ao propor investigar o rural na perspectiva da qualidade de vida e do desenvolvimento local, entende-se que é demasiado complexo estabelecer índices ou resultados sobre essa dimensão humana, dada a diversidade do tecido social presente no rural. Tal diversidade varia desde aspectos culturais até aspectos econômicos, sociais, e até mesmo ambientais. Nesse sentido, parte-se de definições já conhecidas e difundidas que podem nos auxiliar nessa compreensão. Diante disso, afirma Merege(2001)

"Pode-se dizer que qualidade de vida é semelhante à liberdade - não há ninguém que a defina, não há ninguém que não a entenda. Suscita-se então um complexo debate onde são inevitáveis os conflitos de valor, revelando que nossos desafios não se reduzem à escolhas técnicas, mas estão permeados de opções políticas e éticas”.(p.8-9)

Na literatura, o espaço rural é apresentado sobre um duplo aspecto: um lugar maravilhoso para se viver, sobretudo, por suas características bucólicas e mesmo pelo perfil de sua população, mas ao mesmo tempo lugar de atraso daqueles que não deram certo, um lugar impossível de se reproduzir social e economicamente. Para alguns sujeitos ele mantém todas as suas peculiaridades, no entanto, ainda assim só pode ser visto como um lugar de passeio para visitar os parentes, ter o contato com o bucólico, e por isso, extrair dele o que julgam necessário, como afirma Wanderley (2000, p. 40). 
A importância do campo em uma perspectiva histórica está ligada a relação do homem com a terra, principalmente porque dela extraímos a subsistência. Em alguns momentos a vida daquele que habita o campo apresenta-se como alternativa para o burburinho da cidade, da vida na corte. Nesse sentido, Williams (2011, p.15) afirma "Assim, essa vida campestre tem muitos significados: em termos de sentimentos e de atividades; no espaço e no tempo".

Há que considerar que o meio rural nas sociedades modernas apresenta uma diversidade de ocupações e de interesses sociais tornandose atrativo, não apenas pela sua característica agrícola, mas por outras diversas possibilidades como o turismo, lazer, empreendimentos diversificados.Ao que se refere à ocupação desse espaço há um confronto entre três posições diferentes. A primeira evidencia a forma de ocupação atribuída à destinação produtiva do meio rural. A segunda entende tal ocupação como a possibilidade de melhoria na qualidade de vida a que aspira o conjunto da sociedade, sobretudo, para os habitantes das grandes cidades. E a terceira entende esse espaço como um bem coletivo, no sentido de vê-lo não apenas como um local de moradia, mas como um patrimônio ambiental a ser preservado, numa perspectiva de uso não predatório (Ibid. p. 18).

Ao tentar entender qual o tecido social que está habitando as zonas rurais, Ploeg (2008) afirma que as pessoas que decidem morar no espaço rural por opção consistem na categoria daqueles que fazem tal escolha, atraídas pelo repovoamento do campo, no sentido de desenvolverem nesse espaço atividades agrícolas. Nesse sentido, afirma o autor:

"Quanto mais positiva for a avaliação sobre o papel da agricultura na criação e manutenção das qualidades da zona rural, mais capital social existe (...). E quanto mais desenvolvida for a multifuncionalidade na agricultura local, mais o capital social é fortalecido (...). A importância das unidades agrícolas multifuncionais recentes reside não só nos produtos, serviços e no valor agregado associado que elas fornecem, mas também, e talvez especialmente na sua contribuição para o capital social (e, por conseguinte, para a qualidade de vida nas zonas rurais)”(Ploeg, 2008, p.187)

Nesse contexto, essa experiência possibilita olhar para o espaço rural na perspectiva que vai além do produtivo, significa perceber os encontros e trocas que essa experiência de produção proporciona, tanto para seus atores como para as realidades que estão além desse espaço. Significa ainda, que a multifuncionalidade desse local, possibilita a criação de formas diversas no espaço rural, como a criação de lojas, lazer e turismo, oportunidades de emprego, criando assim, uma dimensão econômica que pode favorecer a qualidade de vida para os que ali habitam. 


\section{Metodologia}

\section{Tipo de pesquisa}

A presente pesquisa classifica-se como qualitativa. De acordo comMinayo (1994) a pesquisa qualitativa além de responder a questões muito particulares, está relacionada com um nível de realidade que não pode ser quantificado, de modo que trabalha com o universo de significados, motivos, aspirações, crenças, valores e atitudes, correspondendo a um espaço mais profundo das relações, dos processos e dos fenômenos que não podem ser reduzidos à operacionalização de variáveis. O foco da análise foi a sobreposição de linguagens (oral, imagens, registros apresentados pelas famílias).Precipuamente, considera-se de fundamental importância apresentar o contexto onde estão inseridos os participantes desta pesquisa, no intuito de fundamentar a construção de suas narrativas e discursos, de modo a entender suas falas a partir dos próprios sujeitos, e promover uma maior compreensão dos sentidos atribuídos ao cotidiano vivido, relacionando seus discursos com o universo em que vivem.

\section{Estratégia de coleta de dados}

Os dados foram coletados mediante realização de entrevistas semiestruturadas, registros fotográficos realizados pelos participantes e pela pesquisadora. Em determinada ocasião da entrevista foi solicitado a eles que em posse da câmera, trouxessem o que eles consideram como bom no local em que moram, o que é importante para eles permanecerem nesse lugar, bem como o que nesse lugar lhes remete à qualidade de vida. Para alguns foi o primeiro momento com uma câmera fotográfica, e trouxeram nas imagens muitas representações. Desde imagens dos objetos domésticos, até as fotos dos seus familiares.Optou-se também pelo trabalho com as imagens, por este ser uma forma de produção de linguagem que representa o contexto social a partir de uma articulação mais sensória e afetiva daquele contexto.

O diário de campo foi igualmente utilizado como recurso, uma vez que se trata de instrumento complementar de registro das impressões que o pesquisador traz do campo de pesquisa, e tem o objetivo de sistematizar impressões complementares àquelas coletadas através de outras abordagens diretas com os atores envolvidos.

\section{Resultados e discussões}

\section{O assentamento de reforma agrária como o espaço de enraizamento: $O$ contexto social de Mulunguzinho}

Embora nas casas seja possível perceber a presença de eletrodomésticos contemporâneos, como a geladeira e o fogão a gás, outros 
objetos rústicos permanecem como o fogão a lenha, que segundo as agricultoras deixa a comida mais saborosa, bem como as panelas de barro. Em algumas casas foi possível perceber inclusive, que as panelas de alumínio sempre são mantidas impecavelmente limpas, como se fossem enfeites da casa, ou para demonstrar o zelo pelo lar, mas para o uso diário são preferidas as de barro.

As agricultoras que participaram da pesquisa residem no Assentamento Mulunguzinho, situado a 18 km da cidade de Mossoró no Rio Grande do Norte - Brasil. O Assentamento Mulunguzinho está inserido na região Semiárida do Nordeste brasileiro. A referida região contabiliza 1.135 municípios distribuídos no espaço geográfico de nove unidades da Federação: Alagoas, Bahia, Ceará, Paraíba, Pernambuco, Piauí, Rio Grande do Norte, Sergipe e Minas Gerais, totalizando uma extensão territorial $980.133,079$ km², onde reside uma população de 22.598.318 habitantes, superior as das regiões Norte e Centro-Oeste, e representando aproximadamente $12 \%$ da população brasileira (Insa, 2012).

A região do Semiárido apresenta especificidades tais como, indicadores sociais abaixo da média nacional e regional, além da degradação ambiental evidente em seus ecossistemas. Contudo, a referida região alcançou avanços econômicos e sociais nas ultimas décadas (Silva 2006, p.14).

Dentre os avanços, pode-se citar o fortalecimento da Agricultura Familiar no Estado do Rio Grande do Norte. Em 2006 o Estado do Rio Grande do Norte, através da Lei 8.798 de 22 de fevereiro de 2006, instituiu a Política Estadual de fomento à Economia Popular (Brasil, 2006). A citada política apresenta como diretriz fundamental a promoção da economia popular solidária e o desenvolvimento de grupos organizados autogestionários de atividades econômicas, visando sua integração no mercado e a autosustentabilidade de suas atividades. Essa política de Fomento à Economia Popular Solidária deverá ser fomentada através de programas específicos, projetos, parcerias com a iniciativa privada e organizações não governamentais - ONGs, convênios e outras formas legalmente admitidas. Deve ser articulada, inclusive, com as políticas voltadas para a agricultura familiar.

O Assentamento Mulungunzinho está inserido nesse contexto de mudanças ambientais e sociais que tem conferido à população dos assentados o fortalecimento da Agricultura familiar. A produção total da comunidade divide-se entre o consumo das próprias famílias da comunidade e a comercialização voltada para alguns projetos, tais como, o Programa Nacional de Alimentação Escolar (PNAE), o Programa Aquisição de Alimentos (PAA). Além da atuação na Rede XiqueXique de Comercialização Solidária (Incra,2012).

O assentamento abriga 112 famílias que tem a disposição um posto de saúde e uma escola. O local é conhecido também pela trajetória de um 
grupo de mulheres que decidiram se unir para um projeto de geração de renda, daí adveio aexperiência com produção agroecológica, conhecido como o Grupo de Mulheres Decididas a Vencer.Essa experiência teve início no ano de 1999, e mesmo com dificuldades para produzir, sobretudo, pela problemática do acesso a água, elas continuam a produção para o consumo da família e comercialização do excedente nos quintais de sua casa. $\mathrm{O}$ Assentamento Mulunguzinho foi o primeiro a integrar a Rede de Comercialização Solidária XiqueXique ${ }^{2}$ em que os agricultores e agricultoras movidos pela necessidade de geração de renda, decidiram trazer para a cidade os seus produtos e serem eles/elas mesmos (as) protagonistas desse processo sem a presença do atravessador. Através dessa experiência outros municípios foram se integrando a Rede XiqueXique, o que representa atualmente, uma mobilização social que integra distintos atores, assim como uma diversificação da produção.

O perfil das moradoras entrevistadas é de pessoas que tiveram contato com a agricultura em suas infâncias, foram morar na cidade em bairros periféricos, moravam em casas alugadas, e diante da possibilidade de vir para o Assentamento Mulunguzinho, vislumbraram na Reforma Agrária uma oportunidade de ter a sua casa própria, um lugar seu, e viver da agricultura. Os agricultores e agricultoras entrevistados se encontram na faixa etária entre 33 e 65 anos.O artigo apresenta duas entrevistas que representam uma possibilidade de olhar os moradores do local. Tal recorte decorreu da preocupação em não tolher as entrevistas de modo a não comprometer a compreensão da problemática abordada.

\section{Maria Francisca de Oliveira}

“O bom aqui é criar. Nasci na agricultura, estou na agricultura e gosto muito da agricultura."

A primeira casa a ser visitada foi a de Maria Francisca de Oliveira, 61 anos. Ela e sua família foram os primeiros a chegar ao assentamento no ano de 1992. No ano de 1993, o Instituto Nacional de Colonização e Reforma Agrária - INCRA - comprou a terra e repassou aos assentados. O primeiro espaço da casa a ser visitado foi o quintal, onde Maria, como gosta de ser chamada, cultiva horta agroecológica que é utilizada para o consumo familiar e comercializada as sextas-feiras na cidade de Mossoró, na Rede XiqueXique de Comercialização Solidária.Auxiliam na produção o marido, os filhos de Maria e suas vizinhas que integram o Grupo de Mulheres Decididas a Vencer e respondem pela produção e comercialização de alimentos agroecológicos no Assentamento e na cidade.

A entrevista foi realizada em momentos distintos. No primeiro momento pediu-se que ela escolhesse o lugar em que se sentia bem em sua casa, e o lugar escolhido foi próximo as suas plantas. Iniciou-se a entrevista perguntando o que ela considera bom em viver nesse local, ao que ela responde "O criar. o que eu acho bom aqui é criar. Criar, plantar minha horta. 
O que eu acho bom aqui é isso. Me sinto muito feliz aqui porque eu crio, eu planto".

Durante a entrevista, Maria se sentiu a vontade para relatar sua trajetória no assentamento, das suas alegrias, dos seus filhos e netos. Maria e sua famíliaforam os primeiros a chegar ao Assentamento, e desde então, ela é reconhecida em sua comunidade, sobretudo, pela luta empreendida por reconhecimento político e social, e ainda porque foi uma das mulheres a começar no Assentamento a produção agroecológica.

Quando questionada sobre suas condições de moradia antes de vir morar no assentamento, ela responde: “Em Mossoró eu não tinha nem casa para morar, hoje em dia tenho essa, duas no lote. De vinte anos para cá eu sou feliz, há vinte anos tive apenas sofrimento”.

A renda de Maria e seu marido Luis, advém das suas aposentadorias. Foi possível perceber em seu relato que esse é um fato de satisfação para ela, ao afirmar "Sou aposentada por aqui. Tenho muito orgulho”. A alimentação é garantida pela produção no quintal da sua casa de criação de animais, como galinha, gado bovino, caprino e ovino do qual retiram leite para consumo próprio e carne(no caso dos caprinos e ovinos), e a criação de galinhas, por vezes, torna possível a comercialização de ovos. Os legumes consumidos nessa residência provêm da horta agroecológica. Devido a dificuldade de água nessa região, a produção de gêneros alimentícios é baixa, para a comercialização destina-se o pouco excedente, para complementar a renda familiar. Complementa-se a alimentação com as compras realizadas no supermercado na cidade de Mossoró.

Ao se indagar sobre o que ela diria para alguém que quisesse morar nesse espaço, ela responde: “Fique aqui que é bom, saiba viver. Eu nasci numa casa de taipa, eu era tão feliz. Quando eu vou ao meu lote, estou no céu”. Perguntou-se o que ela entende sobre qualidade de vida, nesse momento ela colocou a sua compreensãosubjetiva, que o lugar em que mora a faz feliz. Embora reconheça que esse espaço carece de melhor infraestrutura para seus habitantes. Nesse sentido ela fala:

"Eu acho que qualidade de vida assim, a gente viver aperriado é muito ruim, mas quando a gente tem o que comer certo, suas coisas certa, já não se preocupa com aquilo ali. Eu me preocupo de acontecer alguma coisa com meus filhos, mas assim de vida eu não me preocupo porque graças a Deus eu tenho. E tudo que eu tenho foi arranjado aqui em Mulunguzinho”.

Há várias pesquisas que desenvolvem modelos conceituais da qualidade de vida, e em várias dimensões, podendo-se citar saúde e meio ambiente. Embora cada uma delas aborde perspectivas diferentes, o que elas terão em comum sempre será a percepção dos sujeitos com 
relação ao seu ponto de vista sobre a qualidade de vida (Martins et al., 2000, p. 65). Ao solicitar os registros fotográficos do que ela considera bom em seu local de moradia, ela informou que nunca havia pego em uma câmera digital, mas se mostrou bastante a vontade com a mesma. Pediu-se que ela trouxesse nas fotos o que a faz feliz em seu local de moradia. A primeira foto realizada foi de seus animais, Figura $\mathbf{N}^{\circ} \mathbf{1}$. Na segunda foto, Figura $\mathbf{N}^{\circ} 2$, Maria fez questão de registrar o seu fogão a lenha, segundo ela, tem que mostrá-lo a quem chega, e mesmo utilizando o fogão a gás, sempre faz questão de cozinhar no de lenha porque deixa a comida mais saborosa.

Figura $\mathrm{N}^{\circ} 1$ Quintal da casa de Maria 19 jul. 2012.

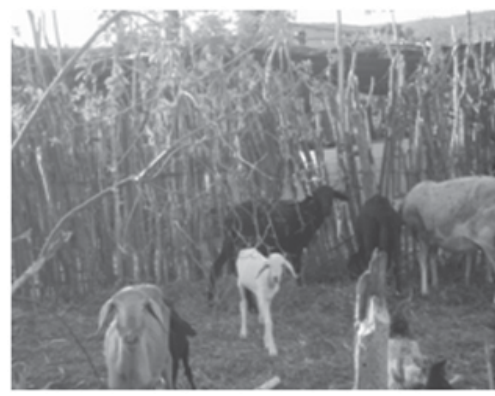

Figura $\mathrm{N}^{\circ} 2$ -

Fogão a lenha da casa de Maria. 19 jul. 2012.

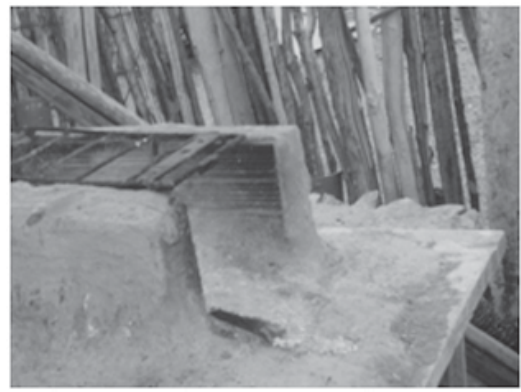

Ao percorrer sua casa, Maria se deteve para registrar a carroça em seu quintal, Figura $\mathbf{N}^{\circ} \mathbf{3}$, que segundo ela foi a primeira carroça da comunidade. Na imagem seguinte, Figura $\mathbf{N}^{\circ} \mathbf{4}$, foi registrada a horta agroecológica cultivada no quintal de Maria. Essa é mantida por ela, seu marido Luiz, e seus filhos que moram vizinhos a sua casa. Maria tem um forte sentimento de pertencimento ao seu local de moradia. Antes de vir morar na agrovila, morou 17 anos no lote - local de produção -, ao que recordar desse tempo, ela fala "Eu passei 17 anos morando no lote. Era tão bom. Eu não troco a minha casinha de taipa por essa boa. É um amor... Eu me dou tão bem. Porque assim eu nasci numa casinha de taipa, só com o barrinho. Eu era tão feliz com meu pai, minha mãe e meus irmãos”. 
Figura $N^{\circ} 3-$

Carroça no quintal de María.

19 jul. 2012.
Figura $\mathrm{N}^{\circ} 4$ -

Horta no quintal de María.

19 jul. 2012.
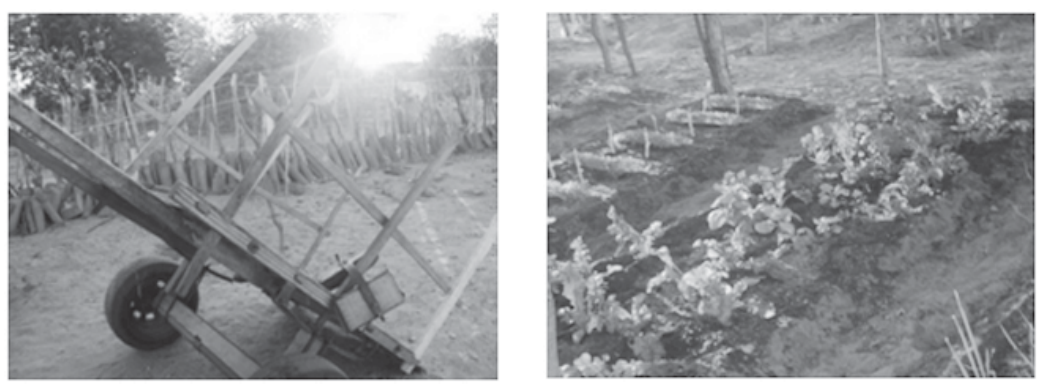

Fonte: (Dados da pesquisa, 2015)

Assim, percebeu-se que o local de moradia de Maria confere-lhe um forte sentimento de pertencimento, de quem tem suas próprias raízes. A relação com a cidade consistiu em uma experiência que ela não gostaria de retomar. No campo ela tem tido a possibilidade de rever sua trajetória, um exemplo é o fogão a lenha que ela mantém em uso, ao mesmo tempo em que convive com as novas lembranças que tem sido construídas, como o cuidado em manter organizadas as fotos dos netos. Através da experiência de Maria, pode-se perceber ainda que para ela no campo é possível a reprodução das atividades agrícolas peculiares a esse espaço, bem como a sua reprodução social, de modo a considerar que nesse espaço encontram-se as condições que a fazem feliz, sendo a possibilidade de criar, ter uma casa arrumada para receber seus netos, ter sua própria renda.

Assim, o espaço rural nas sociedades modernas apresenta uma diversidade de ocupação e de interesses sociais distintos tornando-se atrativo para diversas categorias, não apenas pela sua característica agrícola, mas por outras diversas possibilidades como o turismo, lazer, empreendimentos diversificados, e mesmo os laços afetivos (Wanderley 2009, p. 43).

Percebe-se que em uma abordagem mais ampla, o desenvolvimento das novas ruralidadesem que o rural não é mais percebido apenas pelas suas características e condições físicas, reconhece-se de fundamental relevância a valorização da sua classificação social (Pires, 2007, p. 17). É relevante ainda, considerar que no relato de Maria a construção das liberdades tornou-se possível a partir do acesso a condições concretas que possibilitaram sua reprodução social, como casa própria, a possibilidade de produzir alimentação para sua família e de se inserir em uma rede produção agroecológica. Tais fatores relacionam-se diretamente a construção da sua qualidade de vida. Uma vez que entende-se que a qualidade de vida trata-se 
de uma constituição coletiva. Desse modo, as condições concretas encontradas por Maria e sua família possibilitaram a fixação nesse espaço de moradia, ao mesmo tempo em que tornou possível a sua condição política e social.

\section{Maria Neuza da Silva}

“Hoje eu moro em um palácio, a vista de antes, eu moro em uma senhora casa”.

Maria Neuza da Silva tem 47 anos e mora junto com o marido e dois netos. Mora no assentamento há 08 anos. No início da entrevista ela relatou a experiência de ter morado na cidade, sobre o que ela diz "Quando eu morei na cidade foi só sofrimento”. As lembranças que ela tem desse período, consistem em tempos difíceis em que não tinha casa própria. As condições da residência nesse tempo consistia em estrutura de taipa (pau a pique) com apenas 2 cômodos para 8 pessoas, e quando chovia todos ficavam acomodados em apenas 1 cômodo, sobre esse tempo ela fala "Essa casinha, quando dava o inverno ${ }^{3}$ a água caia e ficava tudo só no barro”.

Hoje, a casa em que mora tem 06 cômodos, conta com aparelhos domésticos como geladeira, televisão, ventilador, liquidificador, torradeira, antena parabólica. A renda da família consiste em menos de três salários mínimos, recebe o auxílio Bolsa Escola que é utilizado para os gastos com as crianças - material escolar, alimentação. Os resíduos orgânicos são utilizados para adubar as plantas, e os resíduos não-orgânicos são queimados a uma distância da casa. Quando morava na cidade a alimentação não era boa, tinha dias que não tinha o que comer. No quintal ela cultiva aves, horta como coentro, cebolinha, frutíferas como cajueiro, bananeira, mangueira, goiabeira, abacate.

O fato lamentado em relação ao seu local de moradia refere-se à dificuldade para plantar devido à falta de água. Em sua fala ela questiona "Como um agricultor vive sem plantar, sem produzir, como fazer agricultura sem água?”. Tal dificuldade incide na ausência de renda, fato que a mesma lamenta. Ao relatar sobre a vida na cidade, ela acessa as memórias dos tempos difíceis em que viveu nesse espaço, e o relaciona como um local em que para ela se tornou impossível de viver, de acordo com sua história de vida. Nesse sentido, ela fala:

"Na cidade tudo é difícil. Tudo que a gente precisa tem que comprar. Aqui não. Aqui é totalmente diferente. Se precisar quebra a lenha, cozinha a carvão, cozinha de todo jeito. Na cidade não, tudo é difícil. Para mim foi a maior dificuldade da minha vida. Lá é bom para quem teve um estudo, um emprego".

A vinda dela para o Mulunguzinhodecorreu da ocasião da vinda dos pais para o assentamento. Em seguida, seu marido veio e toda a família foi 
assentada. Sobre a sua vinda ela relata: "Eu vim praticamente a força, eu não queria vir para cá. Eu já estava tão acostumada com o sofrimento lá, e eu achava tão bom, que eu achava que aqui seria muito pior quando eu chegasse. Hoje me chame para ir para Mossoró que eu não vou mais”. Essa característica de parentesco presente nos assentamentos após a fase de acampamento é apresentada por Marques (2004) ao afirmar:

“A vida adquire certa normalidade no assentamento, e antigas práticas e relações sociais tendem a ser recriadas, estruturando-se o modo de vida dos assentados. Enquanto no acampamento prevalece um movimento de identificação entre os companheiros de luta, apoiado num sentimento de cumplicidade que se origina da partilha das dificuldades do dia-a-dia, na fase de assentamento se observa a tendência a uma retomada gradativa do modelode parentesco, vigente entre os camponeses da região. São estabelecidas relações de afinidades entre eles,por meiodo matrimônio e do compadrio, reafirmando os laços criados no calor dos embates. As relações de parentesco vão assumindo um peso cada vez maior em relação à organização social do grupo, favorecendo o surgimento de um universo de relações mais estáveis, cujas regras de conduta são conhecidas e previsíveis até certo ponto” (p. 150)

Quando questionada sobre os aspectos positivos de residir nesse lugar, ela afirma "A convivência com as pessoas. Estar perto da minha família. Tenho meu pai, minha mãe. Essa é a razão maior de eu estar aqui”. Perguntouse o que ela considera que precisa melhorar, ela apontou que o acesso à água, a problemática das drogas, já presente no assentamento, e ainda a disponibilização de serviços de saúde. Os relatos evidenciam que a relação da agricultora com a cidade é permeada de memórias negativas. O tempo em que não tinha casa própria para morar, e por isso as condições de habitação eram precárias, a fome que a família passou, bem como a morte de uma filha, fato que ela relaciona a má qualidade de vida que a sua filha tinha. No sentido de não se alimentar bem, e trabalhar muito. Sobre a sua opinião em relação a cidade, ela afirma:

"Para mim não tem nada de bom. Lá tem violência. Quando eu preciso ir lá, tem o carro da linha, eu vou lá e compro o que preciso. O que acho de bom são minhas filhas que estão lá. Eu vou lá visitar e pronto, mas para morar eu não quero. O que tem de bom é se a pessoa ficar doente pode chamar uma ambulância, ou se tiver dinheiro paga um táxi e vai”

As memórias que hoje são construídas e relatadas pela agricultora em seu local atual de moradia consistem em bons momentos. Perguntou-se o que ela acha da sua casa hoje, ao que ela responde: "Hoje eu moro em um palácio, a vista de antes, eu moro em uma senhora Casa”. Quando se perguntou o que ela considera de bom ou ruim em morar no espaço rural, a mesma se refere à distância que dificulta o acesso aos serviços de saúde e 
a violência responsável pela falta de momentos de confraternização. Os momentos de felicidade e tristeza estão relacionados à presença e ausência dos seus filhos e parentes, consecutivamente. É importante considerar que esses sentimentos também foram identificados na narrativa de Maria Francisca.

Ao solicitar dela os registros fotográficos que simbolizam a permanência em seu local de moradia, ela pediu que se voltasse na manhã seguinte, por volta das cinco horas da manhã, para registrar os seus pais, que são para ela o motivo de permanecer nesse lugar. Essa imagem é apresentada na Figura $\mathbf{N}^{\circ}$ 5, no momento em que o pai se dirige a cidade. As sextas-feiras, sai cedo de casa, por volta das cinco da manhã, para levar os produtos agroecológicos produzidos por algumas mulheres da comunidade, que são comercializados no espaço urbano, bem como para visitar parentes que moram na cidade. A mulher, nesse mesmo horário, começa as tarefas domésticas como varrer a frente de sua casa. Em seguida, elapediu um registro dela junto com seus pais, Figura $\mathbf{N}^{\circ} \mathbf{6}$.

Ao entregar a ela a câmera para os registros fotográficos, as imagens trazidas pela agricultora consistiram nas fotografias dos seus filhos, figura 7, as plantas em seu quintal, figura 8, que segundo ela não poderiam deixar de ser registradas.

Figura $\mathrm{N}^{\circ} 5$ :

País de Maria Neuza da Silva.

20 jul. 2012

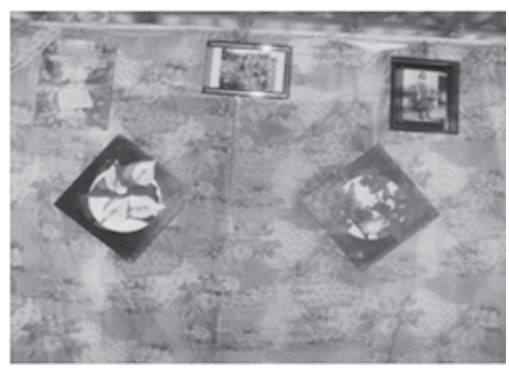

Figura $\mathbf{N}^{\circ}$ :

Maria Neuza com os pais.

20 jul. 2012

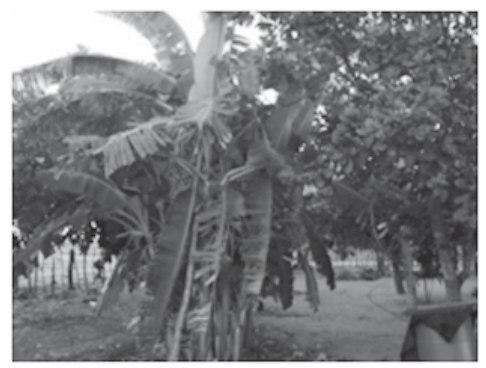

Fonte: (Dados da Pesquisa , 2015) 


\section{Figura $N^{\circ} 7$ : \\ Fotos na parede da casa de \\ Maria Neuza.}

20 jul. 2012

\section{Figura 08: Plantas no quintal de Maria Neuza.}

20 jul. 2012
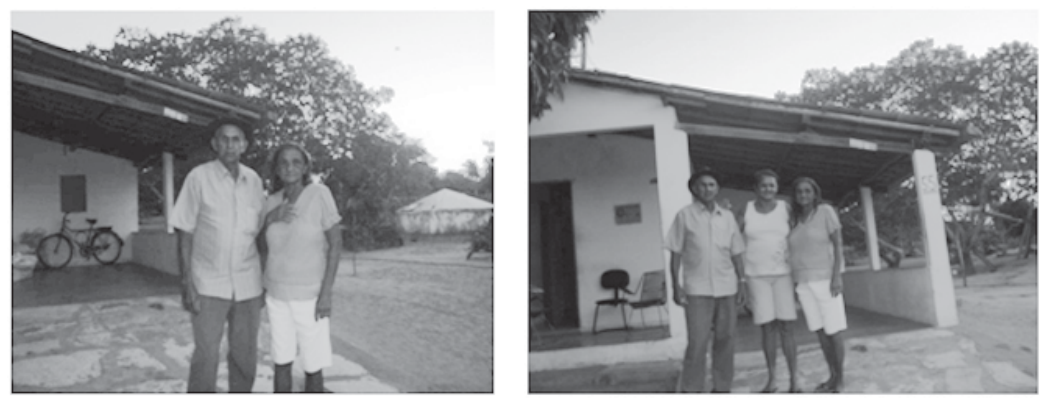

Fonte: (Dados da Pesquisa, 2015)

Nos registros fotográficos apresentados por Maria Neuza, pode-se perceber que o fator determinante de fixação em seu local de moradia diz respeito ao amar e o ser (Vitte 2002). Isso pode ser evidenciado no registro feito dos seus pais, embora toda a dificuldade encontrada por ela no assentamento, como impossibilidade de viver da agricultura devido a falta de água, ela não pensa em nenhum momento em ficar longe dos seus pais. Do mesmo modo, ao apresentar as fotos dos filhos na parede da sala há o sentimento de que estando aí as fotos, eles se mantém perto dela.

Ao conversar sobre o que ela entende por qualidade de vida, sobretudo em seu espaço de moradia, ela respondeu: "Eu acho que para ter qualidade de vida nós temos que ter como trabalhar, porque eu acho que a vida seria bem melhor tendo condições de trabalhar, principalmente pela questão da água para plantar, porque o agricultor precisa de água para trabalhar”. Desse modo, o que se pode perceber no relato da agricultora é que é preciso desenvolver a capacidade endógena do espaço rural, sobretudo a partir de suas especificidades locais, considerando que constitui-se em um espaço de vivência social e não apenas de produção, porém essa vivência pode ser favorecida a partir do desenvolvimento de estratégias que favoreçam ao dinamismo local da agricultura familiar. Nesse sentido, tomase como base o pensamento de (Leff, 2006)

“O alívio da pobreza não depende do aproveitamento do excedente da força de trabalho dos pobres para a construção de infraestrutura básica e para gerar as condições de produção do capital em expansão, mas para mobilização do potencial produtivo dos ecossistemas e das próprias comunidades para seu próprio benefício” (p.484) 
Quando se perguntou o que ela diria para alguém que queira vir morar ali, ela afirma:

“Deixe o inverno chegar, agora a situação está difícil aqui. Eu não viria, vendo como está a situação aqui está difícil eu não viria, mas estando aqui eu não quero sair. Para você ter uma ideia, muitos que moram aqui, trabalham na cidade. Porque aqui não tem como trabalhar. Vive aqui, diz que é agricultor, mas vive de carteira assinada na rua. Porque ele diz eu vou dizer que sou agricultor e matar o meu filho de fome? Não tem como. Aí vai e vem todo dia. Mas porque? Porque não tem como trabalhar aqui dentro. Para o aposentado não é tão difícil porque tem aquele dinheiro certo da aposentadoria. Mas para quem não tem nenhum ganho, é muito difícil. Tem que sair daqui e trabalhar fora”.

No caso de Maria Neuza, entende-se que essa permanência é possível pelos laços afetivos, a presença de seus pais, vizinhos, a sua casa, bem como a própria condição de morar no campo, embora expresse muito claramente as dificuldades de sobrevivência nesse local. Identificou-se, portanto, que apesar de na sua atual moradia ela encontrar dificuldades, considera-se feliz, ao passo que não quer sair desse lugar.

\section{Qualidade de vida e desenvolvimento}

É possível problematizar a permanência no campo, pois ao mesmo tempo em que se percebe no cotidiano dos agricultores a compreensão da perspectiva de convivência com o semiárido (Silva 2006) e estudos como o apresentado por Ploeg(2008) afirmarem que o desenvolvimento eficaz das zonas rurais depende do desenvolvimento das atividades primárias, percebe-se que de acordo com a narrativa da agricultora Maria Neuza há a compreensão da importância de ser agricultor, porém em momentos difíceis como o de seca, como permanecer nessa condição?

Na pesquisa foram identificadas dissonâncias entre os agricultores e agricultoras tais como,auferição de renda. Nesse aspecto, percebeu-se que para as agricultoras que já estão aposentadas há maiores possibilidades de permanecerem no Assentamento, conforme identificado na narrativa de Maria Francisca. Contudo, para os que ainda não acessam a essa política pública, precisam contar com a ajuda dos familiares que moram próximo, fato identificado na narrativa de Maria Neuza. Assim como, para outros há uma intensificação de diversificação de atividades no Assentamento, tais como, mercearias, vendas de produtos advindos da agricultura familiar.

As condições ecossistêmicas encontradas no lócus da pesquisa foram identificadas em circunstâncias de escassez de água, o que implica em dificuldade para produção alimentar das famílias. Em seus relatos, os participantes enfatizam essa problemática como um limitador para a condição de agricultor/agricultora familiar. Essa foi uma inquietação evidenciada na narrativa de Maria Neuza. 
A relação que Maria Francisca faz com a qualidade de vida em seu local de moradia, está relacionada à melhoria de vida que o morar no campo traz para ela, como aposentadoria, possibilidade de plantar, criar seus animais, e ainda estar perto dos seus filhos e netos. É importante ressaltar que o lugar em que ela mora representa recordar momentos felizes de sua vida.

Percebeu-se em seu discurso que Maria reconhece que o lugar em que mora há aspectos passíveis de melhoria acesso à segurança, saúde e educação. Em razão da falta desses serviços, dentre outros aspectos, os agricultores e agricultores mantem uma relação de proximidade com a cidade.

Destarte, faz-se necessário reconhecer que, as condições concretas tais como, trabalho, lazer, felicidade em ter sua casa própria, ter um lugar para criar seus animais, continuar cozinhando no seu fogão a lenha, estão igualmente relacionadas aos aspectos afetivos que o seu lugar de moradia lhes proporciona. A qualidade de vida compreendida por Maria Neuza só é possível se o agricultor tiver como plantar, produzir. Ao mesmo tempo em que esta perspectiva está relacionada aos laços afetivos que seu lugar de moradia proporciona, sobretudo, o contato diário com os pais.

Os aspectos positivos por eles elencados foram casa própria, proximidade dos familiares, trabalho, terra para cultivar, a coletividade e a comodidade da casa própria. Quanto ao que lamentam em seu local de moradia refere-se a falta de segurança, falta de água, falta de transporte; falta de oportunidade para comercialização e falta de políticas públicas que atendam as suas necessidades.

Identificou-se que os sujeitos que contribuíram com a presente pesquisa produzem um discurso aberto, o que significa que não se restringem a relatar aspectos de sua vida presente, bem como acessar as suas memórias. E ainda relatam que transitam de um espaço a outro, porém conseguem estabelecer, ou ter muito claro o que lhes é favorável, e determinante para fixação em seu local de moradia.

Destarte, percebe-se que as moradoras do campo conseguem desenvolver-se socioeconomicamente, estabelecendo relações de afeto com o lugar em que moram, de modo a afirmarem com veemência o que percebem como relevante para a sua fixação no espaço rural. Ademais, percebe-se ainda que as agricultoras entrevistadas veem o seu lócus de moradia como um lugar de reprodução social, em que desenvolvem a sua autonomia e empoderamento, sobretudo, pela possibilidade de obterem sua própria geração de renda.

\section{Considerações finais}

Diante do objetivo de investigar a percepção de agricultoras familiares sobre qualidade de vida no campo, de modo a identificar que tipo de 
modelo de desenvolvimento estava presente em tal concepção, procurouse um percurso metodológico possibilitasse compreender a problemática abordada, uma vez que a qualidade de vida constituiu-se um aporte teórico e empírico para entender o espaço rural em uma abordagem mais ampla do desenvolvimento, tomando como referência Sen (2000). Assim, o potencial ambiental de desenvolvimento sustentável considerado por Leff(2006) como "a possibilidade de pensar e construir uma nova racionalidade de produção, que esteja baseada na articulação de processos ecológicos, tecnológicos e também culturais” (p. 244) foi identificado na trajetória e cotidiano das agricultoras.

Nesse sentido, pensar no desenvolvimento local na perspectiva do desenvolvimento sustentável é reconhecer que, o sentimento de pertencimento das pessoas está igualmente relacionado à valorização dos saberes locais e culturais, bem como a necessidade de preservar os recursos de onde extraem sua sobrevivência, conferindo-lhes a possibilidade de reprodução social.

Os registros fotográficos consistiram em material rico para compreensão do problema aqui tratado, pois permitiu outro olhar de interpretação que se obteve através das imagens reproduzidas pelos sujeitos, bem como pela pesquisadora. Assim, as imagens constituíram em material complementar para as entrevistas, pois os registros apresentavam diferentes formas de percepção sobre seu espaço de moradia. Esses foram traduzidos e interpretados de acordo com o significado que os sujeitos thes atribuíam, conforme sugere Ferrara (1993).

Na presente pesquisa identificou-se que as melhores formas de viver não são exclusividade de um espaço, ao contrário, cada um apresenta suas peculiaridades, ao mesmo tempo em que trazem suas semelhanças, seja pelo fato de o campo não ser mais um espaço isolado, ou mesmo o urbano que vai além das cidades, se tornando um processo que alcança a sociedade em suas mais diversas expressões. Nesse sentido, a cidade irradia o campo, bem como o campo chega até a cidade, cada um mantendo suas peculiaridades, conforme Bagli (2006).

Conforme Merege (2001:25) qualidade de vida diz respeito tanto a condições objetivas como subjetivas, assim, é preciso quantificar essa possibilidade no sentido de apresentar dados que uma vez mensurados, podem ser lidos à luz da subjetividade dos sujeitos. O que implica em entender que a qualidade de vida está relacionada não exclusivamente, mas consideravelmente a autonomia do sujeito, no sentido de entender o que ele tem razão para valorizar.

As estratégias de sobrevivência dos sujeitos investigados consistem nas mais diversas formas na busca de qualidade de vida. Sobretudo, porque enquanto para alguns o imperativo para qualidade de vida é a condição de trabalho, obtenção de renda, para outros é a possibilidade de estar próximo aos familiares. De modo que passam a extrair de diferentes espaços o 
que falta no seu espaço de moradia, mantendo assim inter-relação com outros espaços de reprodução social.

O Assentamento Mulunguzinho pode ser considerado como um lócus de reprodução social que confere aos agricultores e agricultores uma possibilidade de melhoria das condições de vida, assim como acesso às políticas públicas e, apropriar-se da sua condição política cidadã. Contudo, o Assentamento está igualmente inserido em um contexto socioambiental e econômico que demanda para essa região iniciativas de governança que venham romper com um histórico de medidas apenas compensatórias. Sobretudo, porque em suas falas as participantes da pesquisa evidenciam que conhecem a terra em que vivem e produzem.Nesse sentido, torna-se imperativo que para o espaço rural sejam propostas melhorias e soluções que digam respeito aos agricultores e agricultoras que habitam esse local. Conforme Sen (2000) que estejam relacionadas ao que essas pessoas valorizam e têm razão para valorizar. 
Polis, Revista Latinoamericana, Volumen 16, $N^{\circ}$ 46, 2017

\section{Notas}

${ }^{1}$ Entre outros.

${ }^{2}$ A Rede Xique-Xique de Comercialização Solidária tem sede na cidade de Mossoró (RN), situada na região oeste do estado do Rio Grande do Norte. É fruto de um amplo processo de construção coletiva dos grupos produtivos, com a contribuição de um conjunto de organizações da sociedade civil que, atuando em diferentes áreas, lutam pela autonomia e melhoria da qualidade de vida dos trabalhadores e trabalhadoras do campo e da cidade. A Rede comercializa e produz dentro dos princípios da agroecologia e da economia solidária (DANTAS, 2005: 1).

${ }^{3}$ Estação chuvosa na região 


\section{Referências}

Bagli, P. (2006). Rural e urbano: harmonia e conflito na cadência da contradição. Em Sposito, M.E., Whitacker, A. (orgs.). Cidade e campo: relações e contradições entre urbano e rural. São Paulo, Brasil: Expressão Popular.

Brasil (2006), Política Estadual de fomento à Economia Popular Solidária no Estado do Rio Grande do Norte. Recuperado de http:// www.al.rn.gov.br/portal/_ups/legislacao//lo8.798.pdf

Buarque, S. (2008).Construindo o desenvolvimento local sustentável. Rio de Janeiro, Brasil: Garamond,

Carson, R. (1962). Silent Spring.Boston, United States: Houghton Mifflin.

Dantas, I. (2005). A construção da economia feminista na Rede XiqueXique de Economia Solidária. Rev. Agriculturas 2 (3) 1-4. Recuperado de http://aspta.org.br/wp-content/uploads/2014/10/Artigo-7-Aconstru\%C3\%A7\%C3\%A3o-da-economia-feminista-na-RedeXique-Xique-de-Comercializa\%C3\%A 7\%C3\%A 3 oSolid\%C3\%A1ria.pdf

Ferrara, L. (1993). Olhar periférico: informação, linguagem, percepção ambiental. São Paulo, Brasil: Edusp.

Foster, J. (2005). A ecologia de Marx: materialismo e natureza. Rio de Janeiro, Brasil: Civilização Brasileira

Hardin, G. (1968). The tragedy of the commons. En Science 162 (3859) 1243-1248.doi: 10.1126/science.162.3859.1243

Herculano, S. (1998). A qualidade de vida e seus indicadores. Ambiente \& sociedade, 1 (2), 77 - 99. Recuperado de http://www.professores. uff.br/seleneherculano/images/A_QUALIDADE_DE_ VIDA_v2_E_SEUS_INDICADORES.pdf

Instituto Nacional de Colonização e Reforma agrária (2012).Cresce o número de mulheres titulares de terra da reforma agrária. Recuperado de http://www.incra.gov.br/cresce-o-numero-de-mulheres-titularesde-terra-da-reforma-agraria

Instituto Nacional do Semiárido (2012). INSA lança publicação com informações das características da população do Semiárido Brasileiro. Recuperado de http://www.insa.gov.br/censosab/

Leff, E. (2006).Racionalidade ambiental: a reapropriação social da natureza. Rio de Janeiro, Brasil: Civilização Brasileira. 
Idém,(1998). Saber ambiental: sustentabilidad, racionalidad, complejidad, poder. México DF, México: Siglo XXI-PNUMA.

Martins, M. et al (2000). Qualidade de vida, ponto de partida ou resultado final? Ciência \& saúde coletiva, 5(1) 63-81.doi: http://dx.doi.org/ 10.1590/S1413-81232000000100007

Marques, M. (2004). Lugar do modo de vida tradicional na modernidade. Em Marques, M.I. y Oliveira, A. (orgs.).O campo no século XXI: território de vida, de luta e de construção da justiça social,pp. 145158. São Paulo, Brasil: Paz e Terra.

Medeiros, J. (2013). Sustentabilidadeambiental. Em Krachecke, E. (org.).Sustentabilidade ambiental: avanços e desafios do desenvolvimento no Brasil. São Paulo, Brasil: EditoraFundação Perseu Abramo.

Merege, L. (2001).Análise de formações comunitárias em favelas:metodologia, perspectivas e resultados: o modelo da Associação Comunitária Monte Azul (ACOMA).São Paulo, Brasil: Fundação Getulio Vargas.

Minayo, M.C. (1994). Pesquisa social. Petrópolis, Brasil: Vozes.

Pires, A. (2007).Ruralidades em transformação: agricultores, caseiros e moradores de condomínio. São Paulo, Brasil: Annablume.

Ploeg, J. (2008).Camponeses e impérios alimentares: lutas por autonomia e sustentabilidade na era da globalização. Porto Alegre, Brasil: Editora da UFRGS.

Pontual, P. (2002). Qualidade de vida, participação e percepção da população. En Keinert, T. y Karruz, A. P. Qualidade de vida: observatórios, experiências e metodologias. São Paulo, Brasil: FAPESP.

Sousa Santos, B. (2006). A gramática do tempo: para uma nova cultura política. São Paulo, Brasil: Cortez.

Idém. (2002). Para um novo senso comum: a ciência, o direito e a política na transição paradigmática. São Paulo, Brasil: Cortez.

Sen, A. (2000). Desenvolvimento como liberdade. São Paulo, Brasil: Cia das Letras.

Silva, R. (2006). Entre o combate à seca e a convivência com o Semi-árido: transições paradigmáticas e sustentabilidade do desenvolvimento.(tese de doutorado) - Centro de Desenvolvimento Sustentável, Universidade de Brasília, Brasilia, Brasil. 
Vitte, C. (2002). Planejamento urbano, sustentabilidade urbana e qualidade de vida: considerações sobre o significado de cidade e cidadania no início do século XXI. Em Keinert, T. y Karruz, A. P. Qualidade de vida: observatórios, experiências e metodologias. São Paulo, Brasil: FAPESP

Wanderley, M. (2009). O mundo rural como um espaço de vida: reflexões sobre a propriedade da terra, agricultura familiar e ruralidade. Porto Alegre, Brasil: UFRGS. Série Estudos Rurais.

Williams, R. (2011). O campo e a cidade: na história e na literatura. São Paulo, Brasil: Companhia das Letras.

Recibido: 30.03.15

Aceptado: 21.09.15 